\title{
Deslinde jurídico de las descentralizaciones y las autonomías en el sistema político ecuatoriano
} decho privado.

\section{INTRODUCCIÓN}

La finalidad de este documento es suministrar los antecedentes para el deslinde jurídico de los conceptos de descentralización y autonomía, tanto administrativa como política. Para el efecto, se ilustra la discusión con las propuestas de descentralización y autonomía vertidas en el ámbito político ecuatoriano, contrastándolas con la Constitución y el derecho público ecuatoriano y con la doctrina del derecho administrativo, especialmente del español.

\section{ANTECEDENTES}

La centralización administrativa ecuatoriana recién se alcanzó en forma incompleta a mediados de los años setenta. Tal vez por ese motivo, el debate sobre la modernización que se inicia a comienzos de los años noventa, postergó el planteamiento legislativo de la descentralización para fines de ese mismo decenio. Desde el punto de vista jurídico, sin duda que la Ley de Modernización, de 1993, contiene referencias a la descentralización y la hace operativa en su artículo 7, pero la aplicación de esta provisión para el desmantelamiento del INERHI en 1994 y la descentralización de sus actividades de construcción de obra física que se asigna a las corporaciones regionales de desarrollo ${ }^{1}$ constituye un hecho aislado, pronto revertido por las tecnocracias, programadas por décadas de esfuerzo centralizador. Las leyes de distribución del $15 \%$ y descentralización se dictaron en $1997,{ }^{2}$ sin que se hayan reglamentado ni aplicado mayormente hasta la fecha. Por otra parte, su enfoque más que de descentralización administrativa y menos política, es principalmente fiscalista. Asimismo, se incorporan en la reforma y codificación constitucional de 1998 referencias variadas a la descentralizacion, pero siempre de descentralización administrativa. $\mathrm{El}$ artículo primero de la Ley Suprema dice que el Gobierno es "de administración descentralizada", donde antes de la reforma y codificación constitucional de 1998 decía simplemente que el Ecuador era "descentralizado", sin más calificativos.
La discusión jurídica se debe ilustrar también desde la perspectiva de los planteamientos políticos en el Ecuador, que han abundado en los últimos años. ¿Se puede encontrar algo en común entre las diferentes alternativas ofrecidas para la descentralización? La principal característica de los proyectos de descentralización es que, independientemente de cómo se autocalifiquen, sus efectos jurídicos constituyen a lo más una desconcentración y una descentralización administrativa y tributaria. En efecto, para una descentralización política, resulta indispensable una potestad legislativa del mismo nivel que las leyes formales que expide el Congreso Nacional, lo cual, obviamente, tiene que ser debidamente desglosado y delimitado por materias específicas para evitar las superposiciones. Esta es, en todo caso, la esencia del proceso autonómico español y del Estado regional italiano, todavía considerados como Estados unitarios. También se requiere de una clara regulación y control centrales. Ninguno de estos elementos se delinean nítidamente en las propuestas adelantadas que se han podido examinar. En algunas de las propuestas de descentralización se incluye la referencia a una potestad normativa regional, pero se deberá entender que esa normativa será de índole reglamentaria, puesto que no se adelantan los proyectos de reforma constitucional necesarios para que esta potestad se pueda ejercer a nivel legislativo.

La propuesta de Fuerza Ecuador es interesante y razonable, pero adolece de la misma característica de la mayor parte de las propuestas, que la constituye en efecto en una simple descentralizacion administrativa, puesto que expresamente manifiesta: "El gobiemo central mantiene su competencia en ...legislación". Así, según el esquema descrito "[el gobiemo nacional mantiene su competencia en la política exterior, las Fuerzas Armadas, la seguridad nacional, el comercio externo, la legislación e interpretación de la Constitución y demás tareas de carácter nacional". No se encuentran referencias a un parlamento provincial o algo similar. No obstante, algunos de sus enfoques necesariamente suponen la potestad legislativa. Así, cuando propone en la recaudación de tributos que los entes seccionales "podrán ... no cobrarlos para imponer una menor carga tribu- 
taria a su población. Igualmente ... podrán recaudar impuestos adicionales en sus jurisdicciones" ${ }^{\prime 3}$, lo que no se podría llevar a cabo sin una previa reforma constitucional que así lo determine en razón del artículo constitucional sobre la reserva de ley, que enumera las materias que solamente podrán ser normadas por una ley formal del Congreso Nacional (Art. 141). Como se desarrolla más adelante, la descentralización administrativa atribuye a personas jurídicas de derecho público territoriales o funcionales el desempeño de las competencias previamente establecidas legalmente y reglamentadas en su ejecución por el Presidente de la República. Así, la característica básica de tales competencias es que son establecidas y modificadas exclusivamente por ley formal del Congreso o, por delegación, por el Ejecutivo.

Por otra parte, es obvio que una reforma tributaria no necesariamente debería venir de un parlamento provincial y podría perfectamente expedirse por el Congreso Nacional, a solicitud de la provincia, pero con una evidente disminución de la discrecionalidad local.

Un proyecto de reforma constitucional para habilitar la descentralización que se presentó el año 1999 es el que mejor contempla desde el punto de vista técnico jurídico, los requerimientos constitucionales y legales de la descentralización y autonomía política y administrativa $a^{4}$ El esquema de este proyecto, se afirma en su motivación, se ha tomado básicamente del proyecto de reforma constitucional de la comisión llamada de "los notables", en el Gobierno del Presidente Sixto Durán-Ballén. No obstante, en este proyecto la "normativa" provincial tiene un alcance apenas un poco más que reglamentario. Por otra parte, las propuestas manabitas son bastante amplias, pero no suficientemente concretas. Por ejemplo, se puede aprovechar el ensayo que hacen de enumeración de materias y competencias que se reservan para la legislación provincial o regional. Pero hay confusión política inconveniente cuando se propone un consejo de desarrollo provincial en que se juntan indiscriminadamente miembros de elección provincial, funcionarios del gobierno central y miembros de la sociedad civil (Declaración de Manabí).

Hay otra propuesta que se planteó para introducir en la Ley Fundamental la referencia a una "autonomía territorial". No obstante, como se ha observado, la mera expresión de una autonomía "territorial", sin ninguna elaboración, es inconducente sin la referencia explícita en el texto constitucional de sus alcances operativos y principalmente legislativos. Lo mismo se puede decir de la propuesta de la Junta Cívica de Guayaquil y del proyecto del PRE, que consiste esta última en reformar el Art. 224 de la Constitución para añadir la referencia a "comunidades e instituciones autónomas", sin más.

\section{LA DESCENTRALIZACIÓN ADMINISTRATIVA}

\section{La descentralización de competencias} administrativas

La esencia de la descentralización administrativa es la asignación de competencias del Estado a otras personas jurídicas de derecho público. Estas entidades públicas pueden ser territoriales o funcionales. En consecuencia, se discuten en este apartado tanto las clases de descentralización administrativa como las competencias.

\section{La descentralización territorial}

Según la doctrina tradicional, los Estados pueden ser unitarios o federales. Las realidades políticas del siglo $\mathrm{xx}$ añaden a esta clasificación: el Estado regional (Italia) y el Estado autonómico (España). La descentralización y la centralización administrativa son opciones de administración principalmente en el Estado unitario. "Se distingue corrientemente la descentralización territorial y la descentralización por servicios (o funcional)", dice Vedel, "la primera se sustenta en una base geográfica y culmina en la creación de personas jurídicas cuya competencia se determina en relación a un determinado territorio (por ejemplo, la comuna) ${ }^{5}$. En efecto, desde principios del siglo xx Carré de Malberg aclara suficientemente que las figuras de Selbstverwaltung (auto-gobierno) y de descentralización administrativa no son aplicables al Estado miembro de un Estado Federal, "porque el Estado miembro no se administra en virtud de leyes o autorizaciones del Estado federal: mas su administración se funda sobre su propia potestad y voluntad. No será necesario entonces hacer intervenir aquí la idea de auto-administración o de descentralización, sino más bien la de autonomía"6 - debiendo entenderse autonomía política. Es decir, las figuras de descentralización y autogobierno son aplicables solamente a los Estados unitarios.

En aquel momento de la discusión, en el Derecho Público francés se estudia principalmente las características del gobierno comunal o provincial en sus relaciones con la soberanía estatal. Así, Carré de Malberg, citando a Hauriou, manifiesta que "la posesión de derechos de potestades públicas forma precisamente la característica de las personas administrativas descentralizadas", y se pregunta más adelante: “¿Cómo es posible que una comuna, una provincia, puedan administrarse ellas mismas con una potestad de dominio, sin que el Estado del cual dependen, pierda por tanto su carácter unitario?” " La respuesta es que “...las facultades municipales provienen, desde el punto de vista de su eficacia en derecho positivo, de la voluntad del Estado que, consagrando esas facultades naturales, las convierte en derechos propiamente dichos"8.

\section{La descentralización por servicios o funcional}

\section{Establecimientos públicos}

La otra clase de descentralización es la llamada de servicios o funcional, que históricamente aparece con posterioridad a la descentralización territorial. Vedel dice que la descentralización funcional tiene una base técnica, que se manifiesta asignando una actividad determinada a una persona jurídica, bajo la forma de establecimiento público (por ejemplo, la Universidad) 9 . El establecimiento público consta en el Código Civil de Andrés Bello eomo persona jurídi ca de Derecho Público ${ }^{10}$ En esa época, el establecimiento público estaba constituido por hospitales, hospicios y en general casas de beneficencia, mantenidos por el Estado. Por ejemplo, se conoce un informe oficial de 1812 sobre el Hospicio Charendon-Saint-Maurice, cerca de París, a cargo del Ministerio del Interior, donde el célebre marqués de Sade fue condenado a pasar los últimos días de su vida"

Todos los casos de descentralización eonsisten en la atribución de competencias determinadasıaıuna persona juridica diferente que el Estado mismo. Esta persona jurídica puede incluso ser de derecho privado, como se verá inmediatamente. 
Los servicios públicos personificados

El desarrollo del servicio público suministra un decidido impulso a la descentralización en el derecho administrativo francés del siglo XIX, como lo manifiesta a comienzos de siglo xx Duguit: "el aumento del número de servicios públicos implica una descentralización cada vez más grande de tales servicios", añadiendo más adelante que "[l]a forma más nueva y al mismo tiempo más progresiva de descentralización es evidentemente la denominada descentralización funcional (functionariste). Ella ha recibido un comienzo de aplicación en el servicio público de enseñanza superior por la creación de universidades administradas por los profesores mismos bajo el control de la autoridad superior. Este sistema se extenderá ciertamente en el próximo futuro a diversos servicios públicos de orden técnico"12. Finalmente, se desarrollan como establecimientos públicos actividades públicas tan variadas como la empresa pública de extracción de carbón mineral (Charbonnages de France), la institución para la economía energética o la ópera de París. "Esta es la razón, afirma Laubadère, por la cual ciertos autores subrayan que el uso del establecimiento público está desprovisto de significación propia. De la calificación de establecimiento público solamente se deduce la existencia de una persona jurídica pública distinta del Estado o de las colectividades territoriales, a la cual se le reconoce una cierta independencia financiera" "13.

La denominada "crisis" de la noción del servicio público, sobreviene con las realidades del manejo empresarial del Estado que se inicia con las nacionalizaciones inglesas y francesas posteriores a la segunda guerra mundial. La doctrina francesa intentó encajar esta nueva realidad en el antiguo esquema con la denominación de "servicios públicos industriales y comerciales". En todo caso, el surgimiento del Estado empresarial requiere de otras figuras jurídicas para la administración de las unidades productivas, para lo cual se acude a las sociedades anónimas sometidas al derecho privado, pero conservando sus capitales en manos del Estado o en asociación con los particulares, en empresas mixtas.

\section{Las entidades autónomas}

Dentro del ámbito del derecho público, para similares efectos, principalmente empresariales del Estado, se acude también a las "entidades autónomas", es decir personas jurídicas de derecho público con presupuesto propio pero que están sujetas a la "tutela" del Estado. Estas figuras son indudablemente también de descentralización administrativa.

\section{La descentralización a entes reguladores}

Finalmente, un fenómeno reciente surge en los países de la Unión Europea ultimamente, en coincidencia con una práctica tradicional en los Estados Unidos: "El principio comunitario de separación de funciones de regulación y de explotación de actividades económicas de servicio público impone quitar a los operadores nacionales la actividad de regulación, a favor, frecuentemente, de nuevas instituciones independientes" ${ }^{4}$.Garrido Falla denomina este esquema como "la nueva descentralización funcional", señalando su origen en la doctrina alemana, en los "organismos (literalmente, espacios) que, estando dentro del Poder Ejecutivo, se encuentran libres de control gubernamental. ... También nuestro ordenamiento positivo, con mayor o menor éxito, se ha preocupado de garantizar una determinada independencia en relación con estas y otras similares enti- dades. Empero, a mi juicio, el precedente de estas organizaciones independientes está curiosamente en el Derecho anglosajón, ... el origen del Derecho administrativo norteamericano se encuentra precisamente en la creación de las llamadas "Comisiones independientes", la primera de las cuales (Interstate Commerce Commission), surgió en 1887 "'15.

La autonomía administrativa de estas comisiones, denominadas "superintendencias" en Ecuador, no significa que ellas no deban estar sometidas a las normas de organización y el control de legalidad del Derecho Público.

De hecho, la mayor o menor autonomía administrativa que significa la descentralización administrativa, tiene su contraparte necesaria en este tipo de controles de legalidad. En efecto, afirma Garrido Falla que el control es precisamente la característica de la persona jurídica de derecho público: "Bastará el examen de la naturaleza de las relaciones o vínculos que le ligan con la Administración pública de que se trate: si estos son de naturaleza jerárquica o de los que la doctrina conoce con el nombre de tutela, estamos en presencia de un ente encuadrado en la organización estatal"' 16 .

\section{La materia de la descentralización: las competencias administrativas}

Al discutir la estructura de los entes públicos, SANDULLI dice que "sus atribuciones - vale decir las tareas que están llamadas a asumir... - se encuentran frecuentemente repartidas ... entre una multiplicidad de centros, caracterizados por la respectiva competencia (vale decir de aquella parte de las atribuciones del ente, ..., que son conferidas institucionalmente a cada uno de tales centros) ... Estos centros, que pueden ser uno o más, son los órganos del ente

En otro trabajo me he referido a la competencia como el conjunto de funciones que un órgano puede ejercer legítimamente ${ }^{18}$. Así, el concepto de "competencia" da la medida de las actividades que corresponden a cada órgano administrativo de acuerdo al ordenamiento jurídico. La competencia resulta la aptitud legal de obrar del órgano administrativo'. ${ }^{19}$ Esto lo resume Laubadère diciendo que "[l]a regla de la competencia determina en primer lugar las materias que entran en la esfera propia de cada autoridad ${ }^{120}$. Las competencias de las instituciones públicas vienen a ser los límites dentro de los cuales han de moverse las personas jurídicas públicas y los órganos administrativos. Toda atribución de competencia representa al mismo tiempo una autorización y una limitación ${ }^{2 t}$.

Por la norma de la competencia se determina cuándo la actividad del órgano administrativo puede considerarse adecuadamente actividad de la dependencia $o$ entidad respectiva. Para el establecimiento de la competencia se requiere un examen analítico de las normas, puesto que "no todos los órganos pueden lo mismo, ya que entonces no se justificaría su pluralidad". Cuando no se observan tales criterios se incurre en un vicio legal, que afecta a la validez del acto (el vicio de incompetencia) ${ }^{2}$.

Se discute en la doctrina si las competencias se asignan solamente por ley formal o si también pueden atribuirse reglamentariamente. La mayor parte de los autores se inclinan por esta última tesis. Mas, la Norma Suprema ecuatoriana determina que solo la Constitución y la ley pueden asignar competencias: 
Art. 119. - Las instituciones del Estado, sus organismos y dependencias y los funcionarios públicos no podrán ejercer otras atribuciones que las consignadas en la Constitución y en la ley (énfasis añadido).

Esta provisión tiene sus excepciones en las instancias en que la misma Constitución y un par de leyes delegan al Ejecutivo la facultad de atribuir competencias, como por ejemplo, cuando incluye entre las atribuciones y deberes del Presidente de la República "regular la integración, organización y procedimientos de la Función Ejecutiva" (Art. 171,9 .), determinar "las materias de su competencia" de los ministerios (Art. 176), además de las funciones contenidas en la Ley de Modernización (Art. 40 de la Ley de Modernización) e incluso la facultad de transferir competencias a las entidades seccionales, por convenio, que la Ley de Descentralización atribuye al Ejecutivo (Arts. 9 y 12 , Ley de Descentralización).

No obstante que la denominación de "competencia" es la utilizada por la doctrina del Derecho Público, la legislación ecuatoriana emplea indistintamente una serie de términos en forma equivalente, de manera inapropiada, como son: facultades, funciones, atribuciones, responsabilidades (Arts. 9 y 12 Ley de Descentralización). "La función, dice Garrido Falla, no es sino la consideración de la potestad desde el punto de vista de las atribuciones de un órgano administrativo ${ }^{23}$. con lo que concuerda Cassagne, según el cual "[1]a función es, pues, actividad estatal genéricamente considerada"24. Los términos facultad y responsabilidad (así como "deber") son calificaciones de la competencia y se les debe otorgar el significado corriente que tienen en el diccionario. Por otra parte, se considera generalmente que la "atribución" es la asignación de las competencias, aunque en esto no hay concordancia de la doctrina, como lo hace notar Villalva cuando discute la relación entre "funciones" y "atribuciones"25.

En todo caso, para concluir con el tema de las competencias, según el mismo Garrido hay tres tipos de competencias:

...la atribución de competencias puede hacerse de acuerdo con un triple criterio $(o$, si se prefiere, existen tres clases de competencia): 1) el tipo de función (competencia funcional) que se atribuye al organismo o entidad pública de que se trate (potestad normativa, potestad ejecutiva o de gestión y potestad jurisdiccional); 2) el del tipo de materia que se atribuye al órgano (competencia ratione materiae, por ejemplo, obras públicas, aguas, montes, ferrocarriles, etc.); criterio que obviamente es combinable con el anterior, de tal forma que se puede tener en relación con los montes públicos la facultad legislativa (competencia para dictar una Ley de Montes) o, simplemente, la de gestión y administración de dichos montes o aplicación de los preceptos de la ley a los montes privados con la consiguiente intervención administrativa en los mismos; 3) en fin, el del territorio (competencia territorial) dentro del cual se ejercita la competencia atribuida ${ }^{26}$.

Sobre este mismo tema, Real dice que "las funciones institucionales son el conjunto de actividades que basadas en una norma jurídica, deben ser ejecutadas por un órgano jurídico-institucional determinado, como son la formulación de disposiciones y actos administrativos, la planificación, la programación, la ejecución de proyectos, la supervisión central; y, la aplicación de sanción, entre otras”. En consecuencia, divide las "funciones administrativas institucionales" en: política, operativa, control y auditoría, y jurisdiccional ${ }^{27}$.

En mi trabajo sobre la "Gestión Pública Ambiental" hice un ensayo sobre componentes de la gestión del Estado, de los que se pueden desglosar: políticas, planeación y financiamiento, normativa, estructuración institucional, potestad reglamentaria y potestad regulatoria, administración, manejo y operación, seguimiento y control, y sanción y jurisdicción ${ }^{28}$.

La importancia que revisten estas clasificaciones es que permiten aclarar las aparentes confusiones en la descentralización administrativa, puesto que en ocasiones se transfieren algunos componentes y no otros, que se retiene el Estado. Lo mismo ocurre en la descentralización política, cuando se atribuye a la comunidad autónoma la potestad legislativa sobre algunos aspectos de una competencia y no sobre otros. Por ejemplo, existen múltiples instancias donde la Constitución española reserva para el Estado la expedición de la "normativa básica" sobre una materia, encomendando a la comunidad la legislación de desarrollo de esa materia.

\section{Centralización Y descentralización}

\section{EN LA HISTORIA DEL ECUADOR}

El término "descentralización" no es una novedad en la doctrina del Derecho Público ecuatoriano. El publicista ecuatoriano Matovelle distinguía en la segunda mitad del siglo xix:

..centralización. Se designa con esta palabra aquel sistema de administración en que el manejo de todos los intereses y negocios sociales, está confiado únicamente al jefe del gobierno, de cuya voluntad dependen todos los demás agentes de la administración.

Descentralización, es el sistema opuesto al anterior, es decir, aquel en que los negocios propios de las diversas localidades, se administran por sus autoridades especiales, dependiendo éstas de la superior, nada más que en cuestiones nacionales ${ }^{29}$.

Desde ese punto de vista se podría decir que desde el siglo xix existió la descentralización en el Ecuador. Basta por ejemplo, revisar las sucesivas leyes de "Régimen Administrativo Interior", donde el Gobernador provincial ostenta amplias facultades, incluyendo el mando militar, lo que resulta absolutamente necesario en una época de grandes dificultades para el transporte y la comunicación entre las Capital de la República y las capitales provinciales. No obstante, desde el punto de vista de la doctrina actual, en realidad las competencias que las leyes de régimen administrativo interior asignaban al Gobernador no son una descentralización sino una desconcentración, que, al decir de VEDEL es "una técnica de organización que consiste en trasladar importantes poderes de decisión a los agentes del poder central ubicados a la cabeza de las diversas circunscripciones administrativas o de los diversos servicios ${ }^{1130}$, mientras que, como se ha visto, la descentralización transfiere las competencias a otras entidades públicas.

Otra clase de "descentralización" que siempre existió en la República ecuatoriana es la recaudación local y directa de rentas específicas para obras y fines determinados por parte de "juntas" y otras unidades administrativas locales. 
En mi reciente monografía sobre la “Administración Pública ecuatoriana en el siglo $\mathrm{xx}^{\prime}$, cito el ejemplo siguiente:

Tómese el caso de la "Junta Especial de Saneamiento de Guayaquil", que percibía rentas diversas, unas recaudadas por el Tesorero municipal o pagados a la Junta directamente por "los representantes o agentes vendedores residentes en Guayaquil, de fábricas, compañías o casas de comercio del exterior que efectuaren ventas por cuenta de ellas"; por los despachos oficiales de telégrafos del recargo del cincuenta por ciento sobre las tarifas ordinarias por telegramas enviados desde Guayaquil, que se entregarán mensualmente; por los "Agentes o Representantes de Compañias o Empresas extranjeras de navegación ... por cada buque que saliera de Guayaquil"; por los seguros marítimos; por "embarcaciones cargadas"; por "empresas de tranvias"; por adicionales sobre derechos de importación de la Aduana de Guayaquil "y que el Colector de la misma, bajo su responsabilidad personal y pecuniaria, entregará diariamente a la Junta Especial de Saneamiento";

Aunque estas "juntas" no tenían propiamente personalidad jurídica asignada por ley, se manejaban con autonomía suficiente para considerarla una especie de descentralización. Pero en un país como el Ecuador de aquella época sin políticas públicas formalmente expresadas ni una planificación de actividades, y con transportes y telecomunicaciones incipientes, más que una verdadera descentralización tal manejo constituía una verdadera dispersión de las potestades y de los fondos estatales. Así, se puede distinguir en la historia jurídica del Ecuador, especialmente durante el siglo $x x$, un sucesivo ciclo de centralización y de dispersión. La "Ley de Centralización de Rentas" de 1908, afirmaba en su considerando que "el abuso de la Descentralización de Rentas es la causa principal del desequilibrio del Erario, lo que origina un continuo descrédito del Gobierno". En todo caso se dispone que las asignaciones legalmente establecidas en el presupuesto se calculen en cantidades de sucres y no como cuotas de rentas. Larrea critica esta dispersión "del ramo fiscal, en el que se multiplican los impuestos locales y con destino preciso para ciertas obras de interés reducido",33. Asimismo dice sobre el desarollo de la administración pública de comienzos del siglo $\mathrm{xx}$ :

Proliferaron las Juntas, Comités, Institutos, Consejos, Centros, Ligas, Oficinas, Programas, Cámaras, etc., y demás formas de dispersión administrativa, con sus consecuencias de crecimiento desmedido de la burocracia, de poco control y muchos abusos ${ }^{34}$.

La obra política del cinco veces Presidente de la República, J.M. Velasco I. estuvo principalmente orientada a una centralización política y administrativa del país, básicamente administrativa. Este Presidente, por ejemplo, en los años cincuenta vetaba la creación de una "junta de fomento" en los términos siguientes:

... esta serie de entidades autónomas que arrebatan al Poder Ejecutivo sus facultades legales, van creando en el País la anarquía, la confusión de facultades y van socavando el concepto de Autoridad con gravísimo daño para la República;

Esta dispersión de fondos entregados a entidades autónomas perfectamente irresponsables es un desperdicio de los pocos dineros fiscales que tiene el País y que deberían ser empleados por la respectiva autoridad legal y constitucional sin duplicar actividades ${ }^{35}$.

La dictadura militar de comienzos de los años sesenta concluye este esfuerzo centralizador con la supresión de cerca de 1.700 impuestos locales que se unifican en un fondo de donde se realizan los repartos a los diferentes municipios, que es el sistema que con modificaciones existe hasta la fecha. El inconveniente creciente de este sistema es que las permanentes penurias fiscales y los diferentes modos como los sucesivos gobiernos incurren en gastos extrapresupuestarios, impiden hacer la transferencia oportuna de los fondos que legítimamente pertenecen a las entidades seccionales. Asimismo, este reparto se realiza en función de clientelismo político, por lo que fondos que se adeudan legalmente a las municipalidades y consejos provinciales se utilizan por el Ejecutivo para presionar y para compensar favores políticos de los diferentes partidos.

En esta etapa de la historia del Ecuador en los albores del siglo xxi, se ha considerado que resultan suficientemente claros los parámetros de los objetivos nacionales y las competencias establecidas en las diferentes leyes, lo que permitiría que, sin desmedro del manejo unitario del Estado, las provincias y las regiones cumplan con las metas de corto, mediano y largo plazo, en forma directa y recaudando y manejando por sí solas un porcentaje de los recursos fiscales de índole nacional generados localmente. Para esto se requiere no solamente que se traspasen competencias a las provincias y regiones, sino que también se les atribuya la potestad de crear, establecer y definir las competencias mismas a través de las correspondientes leyes y sus reglamentaciones. Esta última cuestión se la tratará más adelante.

\section{LA AUTONOMIA ADMINISTRATIVA EN EL DERECHO ECUATORIANO Y EN LA DOCTRINA}

\section{Las entidades autónomas en el Derecho Público ecuatoriano}

\section{Las entidades autónomas en general}

El concepto de descentralización administrativa está ligado íntimamente al de autonomía administrativa. La figura de la autonomía administrativa está suficientemente desarrollada en el Derecho Público ecuatoriano y consiste en la característica de una entidad pública a la cual se han descentralizado competencias determinadas expresamente en una ley, sometida a la tutela del Gobiemo central, con objetivos que pueden ser de formulación y de implementación de políticas públicas, ejecución de obras y prestación de servicios, que realizan su propio manejo de personal, presupuestario y contractual. Su presupuesto es diferente del presupuesto general del Estado. El Ejecutivo no ejerce un poder de jerarquía sino de "tutela" sobre estas entidades públicas, principalmente a través de su directorio institucional, en la supervisión de sus actividades. Adicionalmente, la autonomía no exime a la entidad pública autónoma de la sujeción a las normas constitucionales y jurídicas nacionales y a los controles de legalidad ejercido por organismos especializados de control del Estado. Asimismo, sus personeros son designados por el Ejecutivo o por el Congreso, o por ambos conjuntamente en los casos de ciertos organismos y por los directorios en las entidades que for- 
man parte de la llamada descentralización institucional, y por tanto sujetos a los controles políticos correspondientes. Finalmente, la expresión de sus actividades se manifiesta a través de "actos administrativos", sometidos al control judicial de su legalidad. El texto constitucional vigente determina que " $[1]$ os actos administrativos generados por cualquier autoridad de las otras funciones e instituciones del Estado, podrán ser impugnados ante los correspondientes órganos de la Función Judicial, en la forma que determina la ley"36. El hecho de ostentar personalidad jurídica y por lo tanto manejar su propio presupuesto, es suficiente para considerar que todas las entidades públicas diferentes del Estado tienen mayor o menor autonomía administrativa, aunque su ley de creación no los califique como "autónomos". Sin embargo, las entidades públicas consideradas autónomas por la Constitución y por sus leyes de origen gozan generalizadamente de mayor autonomía que las demás entidades públicas.

Entidades autónomas contempladas en los textos constitucionales y legales

La Constitución vigente alude a entidades autónomas del sistema nacional de salud (Art. 45), el Instituto Ecuatoriano de Seguridad Social (Art. 58), la Casa de la Cultura (Art. 65), las universidades y escuelas politécnicas (Art. 75), la Defensoría del Pueblo (Art. 96), la Contraloría General del Estado (Art. 211), el Tribunal Supremo Electoral (Art. 209), la Procuraduría General del Estado (Art. 214), el Ministerio Público (Art. 217), la Comisión de Control Cívico de la Corrupción (Art. 220), superintendencias (Art. 222), los gobiernos seccionales autónomos (Arts. 228237), el Fondo de Solidaridad (Art. 250), entidades autónomas de regulación del transporte terrestre, aéreo y acuático y de las actividades aeroportuarias y portuarias (Art. 252), el Banco Central del Ecuador (Art. 261) y el Registro Oficial (Disposición transitoria cuadragésima tercera).

En el texto constitucional anterior a la reforma y codificación vigente, constaba una enumeración ejemplificativa de entidades a las cuales se garantizaba la autonomía de:

... los consejos provinciales, concejos municipales, Instituto Ecuatoriano de Seguridad Social, Banco Central del Ecuador, Banco Nacional de Fomento, Juntas de Beneficencia, Corporación Financiera Nacional, Banco Ecuatoriano de la Vivienda, Banco del Estado, del Tribunal Supremo Electoral, la Procuraduría General del Estado, el Ministerio Público, las corporaciones de fomento económico regional y provincial, los organismos de control y las universidades y escuelas politécnicas ${ }^{37}$.

Finalmente, el Art. 17 de la Ley de Modernización enumera las entidades que no pueden ser reorganizadas por el Ejecutivo, sino solamente por una ley formal:

... se exceptúan de lo dispuesto en este artículo las entidades cuya autonomía se garantiza en ... la Constitución Política de la República, Petroecuador y sus filiales, el Instituto Ecuatoriano de Electrificación, INECEL, la Empresa Estatal de Telecomunicaciones (EMETEL) y la Superintendencia de Telecomunicaciones, cuyos deberes y atribuciones se mantendrán como constan en sus respectivas leyes, de acuerdo con las cuales podrán ser sujetos de procesos de reorganización que garanticen su eficiencia

Este texto legal solamente añade Petrocuador y sus filiales a la lista anterior, donde ya constan las superintendencias, mientras tanto EMETEL como INECEL han sido suprimidas por ley. Estas entidades, además de otras a las que se asigna la calidad de autónomas en sus leyes de origen, como por ejemplo INLAP ${ }^{38}$, etc., ostentan diferentes clases de autonomía. En primer lugar cabe distinguir dentro de ellas a las entidades del régimen seccional autónomo, donde se produce el "autogobierno" propiamente dicho, que Entrena Cuesta prefiere llamar "democracia" ${ }^{\text {" }}$, en cuanto sus autoridades son elegidas por la voluntad de las poblaciones de sus respectivos ámbitos regionales. Asimismo, poseen una limitada potestad legislativa para normar a través de "ordenanzas" en forma generalmente obligatoria en materias tributarias locales y ciertas otras materias determinadas en sus leyes respectivas de organización, así como aprueban sus presupuestos sin revisión ni aprobación de ningún otro órgano estatal. La Constitución ${ }^{40}$ y la Ley de Descentralización ${ }^{41}$ facultan al Ejecutivo para transferir definitivamente a las entidades seccionales autónomas competencias sobre materias enumeradas, a través de la suscripción de convenios. En contraparte, deben rendir cuentas de su gestión ${ }^{42}$. pero en los términos y alcances determinados en forma expresa a la ley. Por ejemplo, están sujetas a las leyes Orgánica de Administración Financiera y Control y de Contratación Pública, pero pueden establecer su propio régimen de personal.

La segunda clase de entidades autónomas son los llamados "organismos de control" por la Constitución: Contraloría General del Estado, Procuraduría General del Estado, Ministerio Público, Comisión de Control Cívico de la Corrupción y las superintendencias ${ }^{43}$. Algunas de ellas, principalmente las superintendencias, tienen su propio régimen de personal y de contratación, dictado por el Ejecutivo, pero otros se sujetan a la Ley de Servicio Civil y Carrera Administrativa y a la Ley de Contratación Pública. Los presupuestos de estas entidades son aprobados por el Directorio del Banco Central o por el Presidente de la República, conforme lo determinado en la Ley ${ }^{4}$. Las máximas autoridades de estos organismos son nombradas por el Congreso o por el Ejecutivo, o por ambos conjuntamente. En esta clase de entidades autónomas también se deberían incluir otras mencionadas en la Constitución como el Tribunal Supremo Electoral, el Instituto Ecuatoriano de Seguridad Social y las universidades y escuelas politécnicas, también con amplio margen de autonomía, aunque solamente las universidades y escuelas politécnicas, de todas las nombradas en este grupo, designan a sus propias autoridades y aprueban sus presupuestos propios, sin participación externa.

Finalmente, existen las entidades que conforman la denominada administración pública institucional ${ }^{45}$. algunas de las cuales sus leyes de origen y otras leyes les atribuyen la calidad de "autónomas", como Petroecuador, por ejemplo. Todas ellas están sometidas a un Directorio, con amplias potestades de supervisión, cuyos miembros son designados en forma mayoritaria por el Ejecutivo o por sus organos dependientes. El Congreso no tiene ingerencia en estas designaciones. La mayor o menor amplitud de su autonomía está determinada por sus propias leyes, sin que la mera expresión de que una entidad es "autónoma" derive algún efecto de esa misma expresión ni nada que no esté autorizado en forma expresa en la normativa legal correspondiente. En el caso de Petroecuador, su ley de creación determina que tendrá su propio régimen de con- 
trataciones, aprobado por el Presidente de la República, y de personal, pero su presupuesto es aprobado por el Congreso Nacional como las demás entidades de la administración pública institucional, con excepción de las llamadas entidades financieras (Banco del Estado, Banco de Fomento, Instituto Ecuatoriano de Crédito Educativo y Becas, Fondo de Solidaridad, etc.), cuyos presupuestos son aprobados por el Directorio del Banco Central, conforme lo determinado en la Ley de Regulación y Control del Gasto Público.

La autonomía y la autarquía en la doctrina y en la legislación comparada

En este tema de los conceptos del Derecho Administrativo, como en otras remas jurídicas, hay que tener presente la observación de Giannini al referirse a la "autonomía" y a la "autarquía": "Tenemos aquí dos vocablos inventados por la doctrina, de los cuales casi todos los autores quieren 'precisar' el sentido. La realidad es que tratándose de nociones abstractas, se hace mucha espesura de cuestiones puramente abstractas; siendo aquí necesario considerar la sustancia, que a veces es algo más bien simple"46.

La mayoría de los autores atribuye a la autonomía una connotación política de autorregulación, reservando el término "autarquía" para el ejercicio de la mayor o menor descentralización administrativa. En otro trabajo, arriba citado, he planteado este tema en los siguientes términos: Cassagne dice que

...la distinción entre 'autonomía' y 'autarquía' vincúlase con las dos formas de descentralización conocidas: la política y la administrativa. En su acepción etimológica, la autonomía constituye una forma superior de descentralización política en cuanto traduce el reconocimiento a la entidad autónoma de la facultad de darse sus propias normas fundamentales e implica una potestad normativa originaria. La autarquía consiste en la atribución que tienen las personas públicas estatales de administrarse por sí mismas, lo cual no es óbice para que, en sentido lato, se consideren las mismas como componentes del Estado.. Es un concepto eminentemente administrativo ${ }^{47}$.

En concordancia con este autor, Giannini dice que "así como la legislación se prolonga en entes con autonomía normativa diversos que el Estado, así la administración (actividad) en igual modo se prolonga con la autarquía"48.

Esta distinción entre "autonomia" y autarquia" es absolutamente necesaria en España, en vista del proceso autonómico de ese país, donde la autonomía se entiende principalmente en su acepción de "autonomía política". En su obra sobre el Estado autonómico, el autor español Ferrando Badía establece la distinción entre autarquía y autonomía diciendo que "mientras la primera se caracteriza por el ejercicio de la potestad reglamentaria, la autonomía se caracteriza por el ejercicio de la potestad legislativa" ${ }^{\prime 49}$. Pero ni siquiera en España, la distinción entre ambos términos se encuentra plenamente establecida, puesto que la vigente Ley de Entidades Estatales Autónomas de 1958, reforma-. da por la Ley General Presupuestaria (texto refundido de 1988) se refiere a los "organismos autónomos", definidos como: "entidades de Derecho público creadas por la Ley, con personalidad jurídica y patrimonios propios, independientes de los del Estado, a quienes se encomienda expresamente en régimen de descentralización la organización y administración de algún servicio público y de los fondos adscritos al mismo, el cumplimiento de actividades económicas al servicio de fines diversos y la administración de determinados bienes del Estado, ya sean patrimoniales o de dominio público" (art. 2), que es una definición que guarda concordancia con la utilización del término de autonomía en el Derecho Público ecuatoriano. En cambio, el vocablo autarquía no se utiliza en la terminología administrativa ecuatoriana ${ }^{50}$.

Pero los autores citados se quedan cortos en su definición de autonomía, especialmente cuando en forma generalizada dicen que es la potestad para dictar su normativa propia. Por lo menos en el Ecuador, esta no es una característica que pueda servir para diferenciar estas entidades públicas de otras no llamadas "autónomas". En primer lugar, los ministerios, que son dependencias y no entidades, están autorizados para dictar "las normas, acuerdos y resoluciones que requiera la gestión ministerial", sin que eso los convierta en autónomos.

Claro que hay que convenir que ellos actúan en representación del Presidente de la República. Por otra parte, todas la entidades públicas, sean o no calificadas legalmente como autónomas, dictan su propia normativa interna, como son reglamentos orgánicos funcionales, de personal, de contratación, etc. Existen entidades que sí expiden normativa que se aplica más allá del ámbito interno institucional: las municipalidades y consejos provinciales dictan ordenanzas sobre materias legalmente adjudicadas, que establecen mandatos generalmente obligatorios sobre los habitantes del territorio; la Contraloría dicta "regulaciones de carácter general para el cumplimiento de sus funciones" (Art. 211 de la Constitución); el directorio del Banco Central expide "regulación con fuerza generalmente obligatoria" (Art. 263 de la Constitución). Pero otras entidades consideradas también autónomas limitan su normativa al régimen interno institucional. En consecuencia, parece más acertado el análisis de Entrena que incluye la posibilidad de dictar normas como uno de los sentidos del término autonomía, pero que también describe otros dos sentidos: la propiedad de los entes administrativos menores de constituir su propio ordenamiento, que solo podrán ser normas internas; en la otra acepción, define la autonomía como "capacidad general de autodeterminación"s) que es una característica que refleja más adecuadamente propiedades que en mayor o menor grado ostentan las entidades públicas consideras "autónomas" por el Derecho Público ecuatoriano.

\section{LA POTESTAD LEGISLATIVA COMO ESENCIA DE LA DESCENTRALIZACIÓN Y LA AUTONOMÍ POLÍTICA}

\section{¿En qué consiste la autonomía política?}

Una vez esclarecido el alcance puramente administrativo que tienen en el derecho positivo ecuatoriano los términos de descentralización y de autonomía, cabe examinar la descentralización y la autonomía de índole política. Será útil recordar que la característica de la descentralización administrativa consiste en la transferencia que el Estado hace de competencias propias, atribuyéndolas a personas jurídicas de derecho público -entidades públicas-para cuyo ejercicio les concede grados variables de autodeterminación.

Para expresarlo simplemente, la autonomía política consiste en "determinar su competencia, exclusivamente 
en virtud de su voluntad, es decir de fijar libremente por sí mismo las tareas que desea cumplir". Así, la autonomía política se puede definir como "la competencia de la competencia", en palabras de CARRE DE MALBERG ${ }^{\text {s2 }}$ de Malberg. Debe aclararse, no obstante, que, a comienzos del siglo xx, cuando este publicista hacía tal afirmación, solo había tres realidades estatales: el Estado unitario, el Estado federal y la confederación de Estados; aunque ésta no puede considerarse propiamente un Estado. El Estado regional italiano surge recién en 1941 y el Estado de las autonomías español se concreta en la Constitución de 1978, aunque con antecedentes en la Constitución de 1931. En efecto, el autor francés citado se estaba refiriendo a la potestad estatal, sea ésta del Estado unitario o del Estado federal, pero también de los estados miembros de este último ${ }^{53}$.

\section{¿Reparto de competencias o reparto del poder?}

Pero no se debe confundir este reparto de competencias con una "división del poder" como se ha afirmado equivocadamente: no se trata de "una reasignación de los poderes del Estado", ni es apropiado decir que "a la clásica división de las funciones judicial, ejecutiva y legislativa, la descentralización añade la división del poder entre niveles de gobierno"s4. La potestad estatal es una sola pero se puede decir que existe un poder legislativo, un poder gubernativo, un poder jurisdiccional, etc. poderes que no pueden dividirse en absoluto. Sí existe, en cambio, una división de funciones que ejercen uno o más poderes en forma predominante. Así, la función judicial ejerce el poder jurisdiccional pero este poder es ejercido también por el Tribunal Constitucional que no es parte de la función judicial - y por la función legislativa. Esto lo ha explicado oportunamente Carré de Malberg: “... la limitación de la potestad estatal en cuanto a los objetos sobre los cuales se puede ejercer, no implica absolutamente una división de la potestad en sí.... La verdad es que el Estado posee una potestad completa desde que conserva íntegramente las diversas funciones del poder... Si uno de estos tres poderes existiera solo en beneficio de una sola colectividad, entonces sería verdad decir que esta colectividad no posee más que un fragmento de la potestad estatal... Sin duda, existe reparto de competencias..."ss.

\section{Diferencia principal entre federalismo y autonomía}

Ahora bien, es el momento de afirmar que la distinción entre el Estado federal y el Estado (unitario) regional italiano y el Estado (unitario) de las autonomías español, se sustenta más en su origen que en los mayores o menores poderes que puedan ostentar los Estados miembros del Estado federal o las regiones y comunidades autónomas. El Estado federal se origina en la voluntad de Estados soberanos de unirse en una federación, acordando la soberanía y deteminadas potestades a ese Estado federal. En efecto, se afirmó del término "autonomía" que su mera enunciación no le atribuye por sí misma características específicas a la entidad así calificada, sino que esas características deben provenir del contenido de su ley de creación. Asimismo, la expresión genérica de estado miembro de un Estado federal, no significa forzosamente que tal estado miembro ostentará las mismas facultades que un estado de los Estados Unidos de América, de la República Federal Alemana o de los Estados Unidos de Brasil, sino que necesariamente habrá que estudiar las constituciones respectivas para establecerlo con certeza. Por eso dice acertadamente Carré de
Malberg que "[e]s cierto que puede existir de hecho mayor descentralización en un Estado unitario que en un estado federativo"'s6.

\section{El federalismo en la historia del Ecuador}

Por eso, en el Ecuador contemporáneo resultaría anacrónico el establecimiento de un Estado federal, puesto que por definición un Estado federal se constituye a base de la unión de Estados soberanos que se reúnen y ceden parte de sus competencias al Estado federal. Sí hubiera sido apropiado, por lo menos doctrinalmente hablando, que Guayaquil se integre a Colombia en 1824 como un estado miembro de un Estado federal. Recuérdese que entre el 9 de octubre de 1820 y el 24 de mayo de 1822 , Guayaquil fue materialmente - a falta de declaración formal - un Estado soberano, es decir no estuvo sujeto a la Corona española ni a ningún otro Estado. En cuanto a su territorio, estaba compuesto por toda la Costa ecuatoriana, con la excepción de Esmeraldas y su población era de alrededor de 70.000 habitantes. De esta época dice Luis Alberto Sánchez: "Guayaquil titubea sobre su futuro destino; además hay muchos que preferirían verla convertida en ciudad-libre, como las hanseáticas"157. En la misma línea de pensamiento, debe citarse la primera Constitución del Ecuador ${ }^{58}$, que se autodenomina "Constitución del Estado del Ecuador en la República de Colombia" y su Art. 2 que declara: "El Estado del Ecuador se une i confedera con los demás Estados de Colombia para formar una sola nación con el nombre de REPÚBLICA DE COLOMBIA"s9. Por otra parte, la otra opción es de establecer el Ecuador no como un Estado unitario sino como un Estado federal: "La tentación del federalismo debió ser grande, tanto por los numerosos ejemplos de países americanos, como por el aislamiento geográfico de varios sectores de la patria" ${ }^{60}$. Sobre otras épocas en que se ha contemplado la opción federal, este mismo autor dice:

Sí se han producido movimientos jurídicos tendientes a una mayor descentralización y en algunos casos éstos han lindado con un larvado federalismo, como sucedió en 1835 y en 1861, al establecer las Constituciones la elección de ternas presentadas por asambleas locales para el nombramiento de Gobernadores y hasta de Jefes Politicos cantonales. Este sistema, dos veces ensayado con pésimos resultados, debilitaba excesivamente el Gobierno central, politizaba exageradamente a los pueblos y no contribuía a la unidad sino a la disgregación nacional.

Las graves crisis políticas, sobre todo las de 1859 y de 1883 produjeron también el fenómeno del establecimiento de gobiernos locales, pero estos tuvieron carácter esencialmente transitorio, hasta superar las situaciones anárquicas, y no pretendieron consolidar una descentralización total del poder político ${ }^{61}$.

También dice este jurista que "Alfaro tenía ideas federalistas, pero desde que estuvo en el poder gobernó con sentido de unidad nacional y con un centralismo más acentuado que en períodos anteriores"62.

\section{El Estado autonómico español y las propuestas ecuatorianas}

La actualización del debate sobre la descentralización en todo el mundo desde la década de los ochenta, apunta principalmente a la descentralización administrativa. En Francia se ha visualizado como "el problema fundamental de la descentralización” "[1]a repartición de competencias 
entre diferentes niveles de colectividades y de la administración". Son indudablemente interesantes las experiencias del federalismo alemán y belga, así como otras experiencias europeas ${ }^{63}$. Pero en el Ecuador la experiencia y el modelo autonómico español son los que han despertado mayor interés y expectativas. Así, por ejemplo, el proyecto sobre la organización territorial del Estado en comunidades o regiones autónomas, presentado a mediados de 1991 por la Facultad de Derecho de la Universidad Católica de Guayaquil, fue "inspirado en la legislación española" 64 . El artículo sobre competencias copia literalmente el texto respectivo de la Constitución española de 1978. Pero tanto este proyecto de descentralización cuanto los esquemas diseñados con posterioridad no avanzan hacia la esencia de la verdadera autonomía, cual es, como se ha visto, el asumir "la competencia de la competencia", lo cual solamente es posible en el momento en que las provincias o regiones autónomas asumen la potestad legislativa que les permite formular y definir las competencias. Las variadas referencias en el texto constitucional ecuatoriano reformado y codificado en 1998 consideran exclusivamente la descentralización administrativa consistente en una transferencia de competencias a las entidades del régimen seccional autonómo, en la línea de la Ley de Descentralización de 1997, forma de descentralización que permanece mayormente inaplicada hasta la fecha. Una de las razones para esta falta de aplicación de la Ley es que se sustenta en un esquema que necesita del acuerdo de la Administración Pública acerca de los temas y del alcance de la descentralización y por lo tanto se sustenta en la voluntariedad del Ejecutivo.

\section{Conclusión: las opciones del ejercicio legislativo de las comunidades autónomas}

Por otra parte, el sistema español permite a la Comunidad autónoma asumir la potestad legislativa para expedir normas con rango de ley del Congreso en materias determinadas en el Art. 148 de la Constitución española, las que pertenecerán en forma exclusiva a la Comunidad autónoma, lo que se deberá concretar en el Estatuto correspondiente. Asimismo, se definen las competencias que permanecen como exclusivas del Estado (Art. 149 de la Constitución). Sin esta potestad legislativa, es decir sin la atribución de "la competencia de la competencia" no existe una verdadera descentralización política ni autonomía política. Pero, además, algunas de estas competencias comprenden la expedición de la normativa básica o las bases generales, que autorizan a las comunidades autónomas a expedir la legislación de desarrollo en estas materias reservadas al Estado, encuadradas en la legislación básica o de bases generales dictadas por las Cortes. Sobre estas materias reservadas al Estado todavía es posible para las Cortes el disponer la delegación legislativa a favor de las Comunidades autónomas, que permite a éstas expedir normas con rango de ley sobre las indicadas materias. Finalmente, también es posible que el Estado transfiera o delegue a las Comunidades, mediante ley orgánica, "facultades correspondientes a materia de titularidad estatal que por su propia naturaleza sean susceptibles de transferencia o delegación. La ley preverá en cada caso la correspondiente transferencia de medios financieros, así como las formas de control que se reserve el Estado" (Art. 150 de la Constitución española).

1. DE 2224. Expídese la "Organización del Régimen Institucional de Aguas". Suplemento RO 558 del 28 de octubre de 1994.

2. L. Ley Especial de Distribución del $15 \%$ del Presupuesto del Gobierno Central para los Gobiernos Seccionales. RO 27 del 20 de marzo de 1997; L. 27. Ley Especial de Descentralización del Estado y de Participación Social. RO 169 del 8 de octubre de 1997.

3. Mata Espinel, Humberto. "Proyecto de autonomías provinciales ecuatorianas", en: Francisco Muñoz J. (Compilador). Descentralización. Tramasocial. Quito, 1999. pp. 187 y $190 ; 183-201$.

4. Proyecto presentado por el Dip. Raúl Gómez, del Partido Social Cristiano.

5. Vedel, Georges y Pierre Devolvé. Droit Administratif (12a. ed. actualizada). Presses Universitaires de France. París, 1992. T. 2, p. 399.

6. Carré de Malberg, R. Contribution a la Théorie Générale de l'État (Sirey, 1920). Reimpresión del CNRS. París, 1962. T. I, pp. 170-171.

7. Ibid. p. 179.

8. Ibid. p. 186.

9. Vedel. Ob. cit. p. 399.

10. Código Civil del Ecuador. Art. 585: “... corporaciones de derecho público, como ... los establecimientos que se costean con fondos del erario".

11. "Notice sur l'hospice de Charenton" de Hippolyte de Colins (1812). En: Sade, Marquis de. Journal Inedit, con un apéndice de Hippolyte de Colins. Gallimard. París, 1970.

12. Duguit, Léon. Traité de Droit Constitutionel (3a. ed., 1928). Fontemoing \& Cie. París, 1927. T. II, p. 66.

13. Laubadère, André de; Jean-Claude Venezia; y Yves Gaudamet. Traité de Droit Administratif. (12a ed.). LGDJ. París, 1992. T. I, p. 238.

14. Cohen-TAnugi, Laurent. La Métamorphose de la Démocratie Française. Gallimard. París, 1993. p. 53-54. 
NotaS

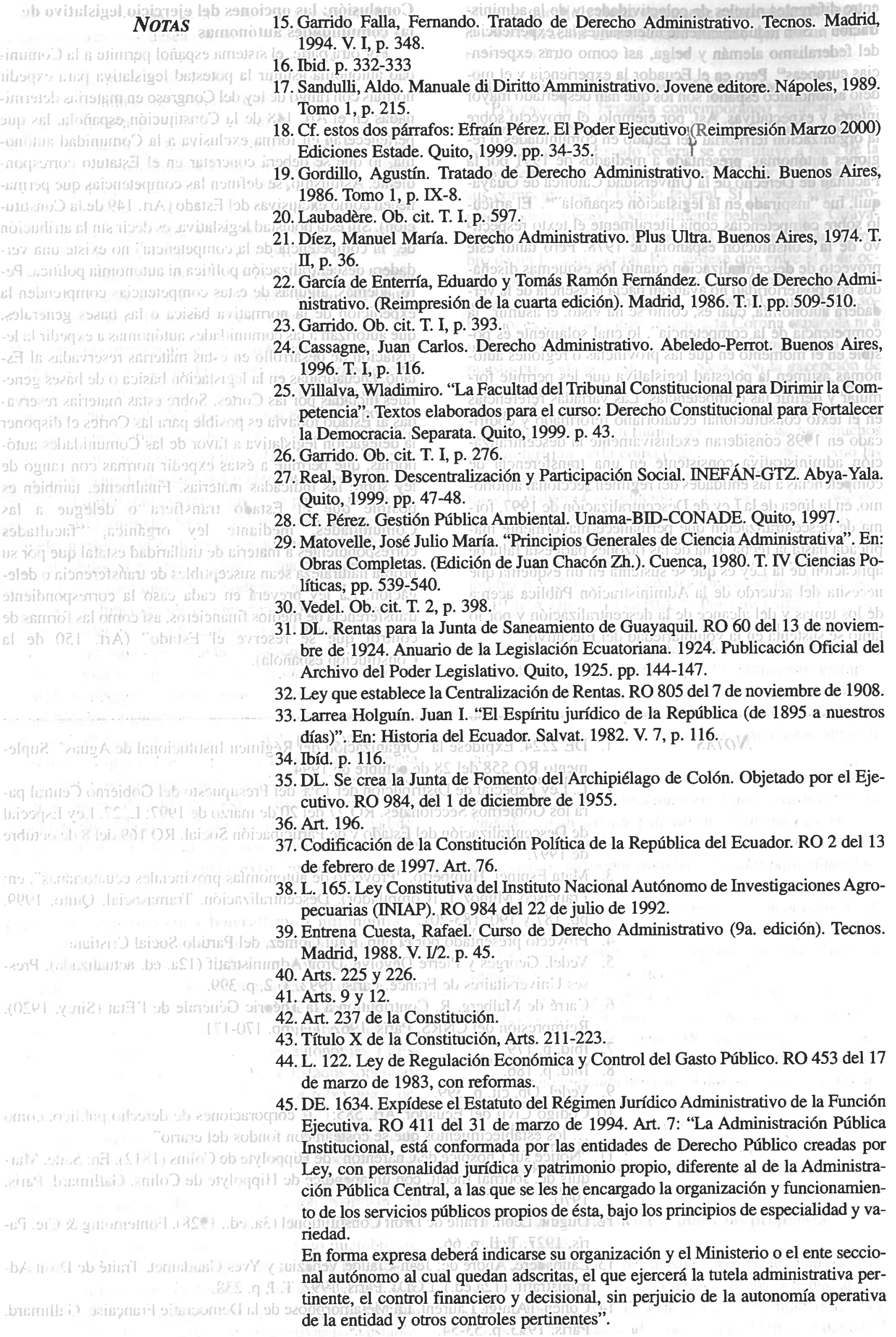



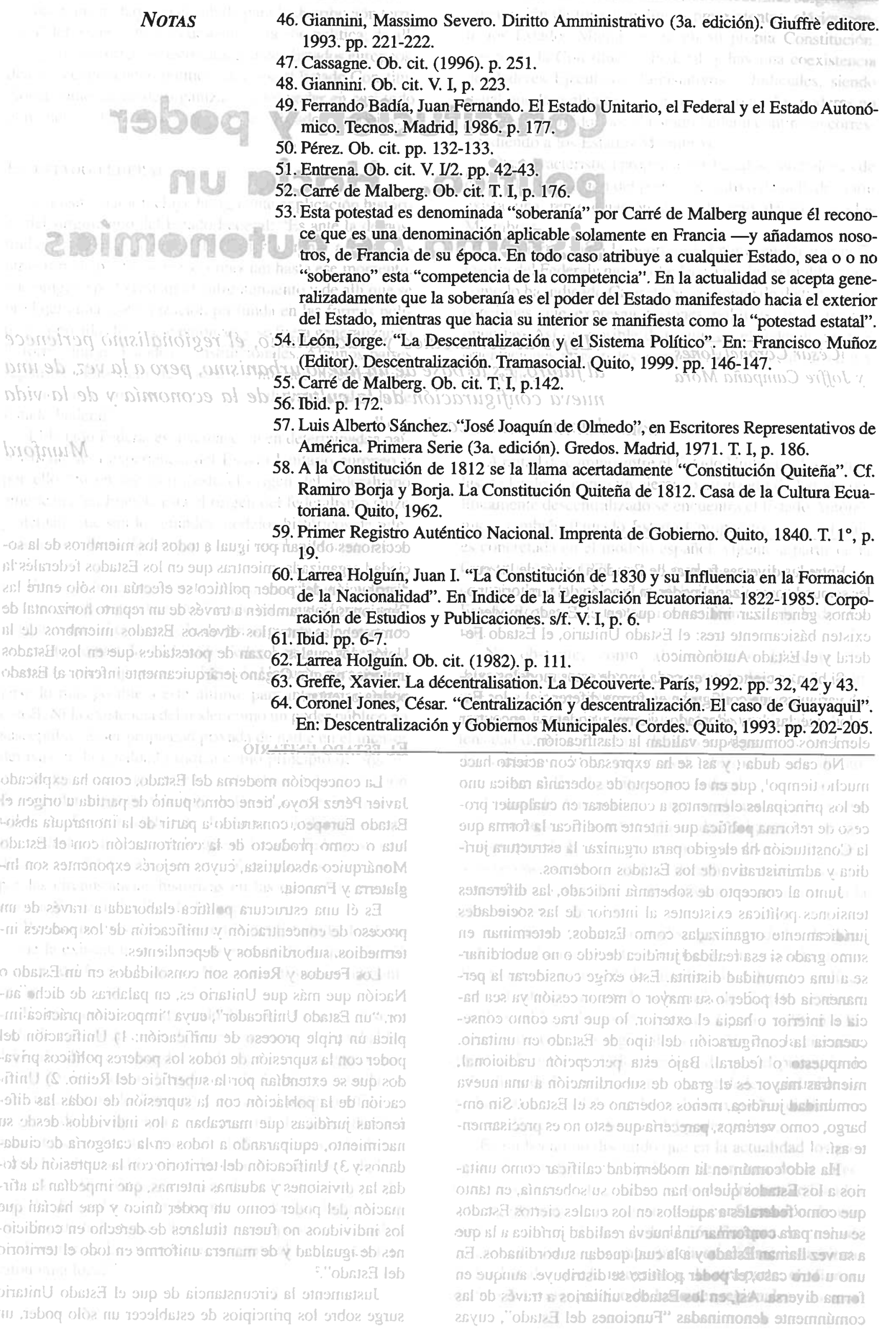